\title{
O Hotel Pro Forma não está a ficar mais dramático
}

\author{
Maria Carneiro
}

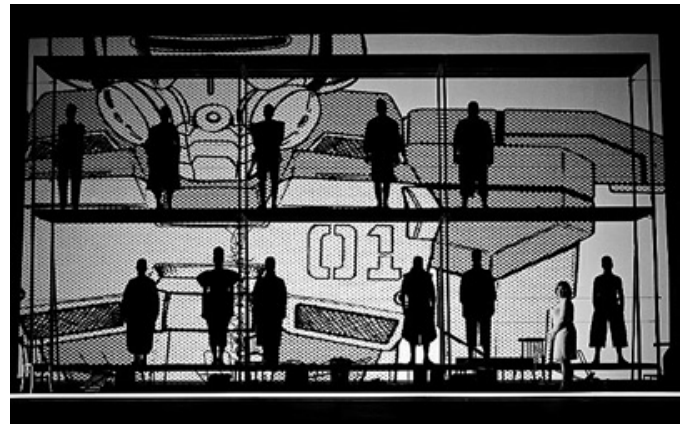

A companhia dinamarquesa Hotel Pro Forma é conhecida pelo seu teatro visual e musical. Começou por ser o Billedstofteatre (Teatro da Imagem Material), um grupo de pessoas que fazia performances sem palavras ou música, em espaços não tradicionais - como museus - durante 0 dia. As performances visuais não tinham qualquer preocupação com o dramático: a criação baseava-se em principios performativos e de exibição. A directora artística, Kirsten Dehlholm, começou a sua carreira como artista visual a trabalhar com têxteis, depois interessou-se pelo espaço, e mais tarde pela forma humana.

Depois de nove anos a criar performances de material visual, o grupo passou por uma mudança profunda. Em 1985 o Hotel Pro Forma substitui o Billedstofteatre. Juntamente com a mudança de nome, chegou a mudança de estética. A companhia começou a criar para palcos convencionais e a usar textos nos seus espectáculos. Neste momento a companhia começa a abraçar o dramático de uma forma muito particular. Apesar da mudança em direcção ao dramático, a verdade é que a companhia nunca o concretizou inteiramente, pois, afinal, não é disso do que se trata.

Durante mais de 25 anos o Hotel Pro Forma tem sido um teatro de texto, embora nunca ninguém tenha podido escutar um diálogo em palco. A companhia continuou a ser um teatro de texto não dramático, evitando o enredo. Também tem evitado uma tónica dramática dominante na representação/apresentação. Com respeito ao teatro que faz, o Hotel Pro Forma não está a ficar nada mais dramático.

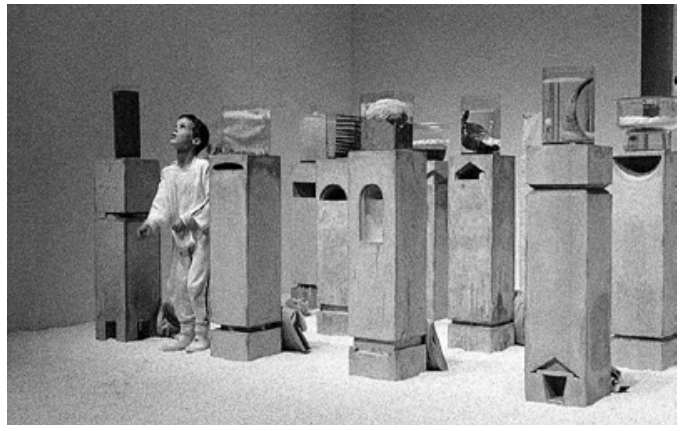

Nas palavras de Kirsten Dehlholm:

Nós não fazemos teatro naturalista que conta enredos através de acções. Nós contamos por imagens, música e ambiente - por aí criamos uma estrutura reguladora que é diferente para cada produção. (http://www.rehearsalmatters.org/interview/kirsten-dehtholm, trad. minha)

Esta é uma descrição sumária de como trabalha o Hotel Pro Forma. É ainda um teatro fortemente visual e de imagens, partindo sempre do desenho do espaço cénico, a colocação do público e do teatro como conceito. Este conjunto de premissas é conhecido como triplaencenação (triple-staging): a encenação do espaço, a encenação do olhar e o teatro como conceito. Todos os espectáculos são sobre o teatro como forma de arte. A companhia procura interrogar as condições da arte numa situação de espectáculo: oferece ao público a oportunidade de ver investigações sobre a luz, o som, o espaço e o texto. Como escreveu Lars Qvortrup:

Mas o espaço não pode ser ilustrado fora do espaço, o tempo tem de ser narrado pelo tempo - e por isso tem de haver uma nova técnica de narrativa. Alguém não se pode colocar fora do assunto e, como o divino narrador, dizer 'Era uma vez...'. Alguém tem de se colocar dentro do assunto e a partir dai empurrar para fora em

direcção às suas bases, de modo a que o projecto de teatro tenha de demonstrar 'o teatral'. (Theil/ Dehlholm 2003: 179, t.m.)

Apesar da falta de palavras e de diálogo, bem como do facto de os performers serem estáticos e o ritmo lento, 


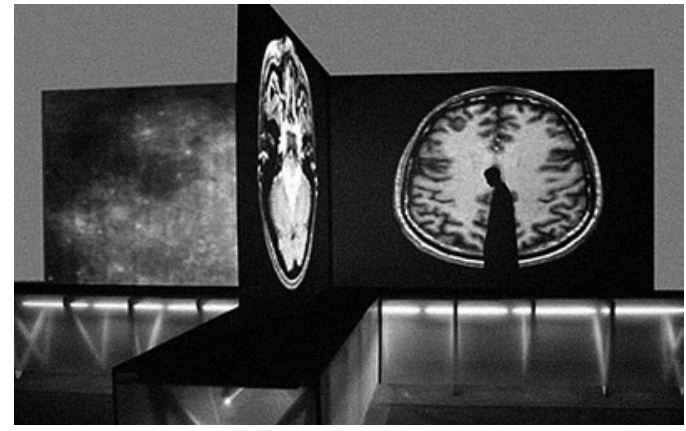

as produções do Hotel Pro Forma implicam uma estrutura narrativa que é facilmente sentida pelo público. Por outras palavras:

0 que acontece quando alguém não quer simplesmente contar uma história, mas narrar a narrativa? (/bid: 179, t.m.)

Ao tomar em consideração o uso do texto e a apresentação de espectáculos em espaços tradicionais, a companhia começa a lidar com a convenção teatral. 0 Hotel Pro Forma tem uma grande vontade de trabalhar com condições teatrais pré-determinadas a fim de explorar e investigar o meio em si, mas não começou a trabalhar na configuração de teatro, por isso não depende dela. Tem adoptado, de forma deliberada, o espaço de teatro e o texto para teatro, mas para os desafiar. Uma certa falta de raizes está sempre presente, e essa parece ser precisamente a forma de problematizar a ideia de teatro: a companhia tenta uma redescoberta das formas teatrais.

Falando sobre uma mudança estética, temos de tomar em consideração as referências artísticas da companhia. Com raizes fortes nas artes visuais e na arquitectura, o trabalho, que desenvolve, começa com o desenho do espaço na sua relação com a luz, o som, os performers e a colocação do público. A criação de espaços - e a espacialidade, em geral - é, para eles, crucial em qualquer projecto. Para além disso, todos os projectos do Hotel Pro Forma transmitem uma sensação de ordem, revelam uma procura de uma ordem interna das coisas. É também importante assinalar que a companhia

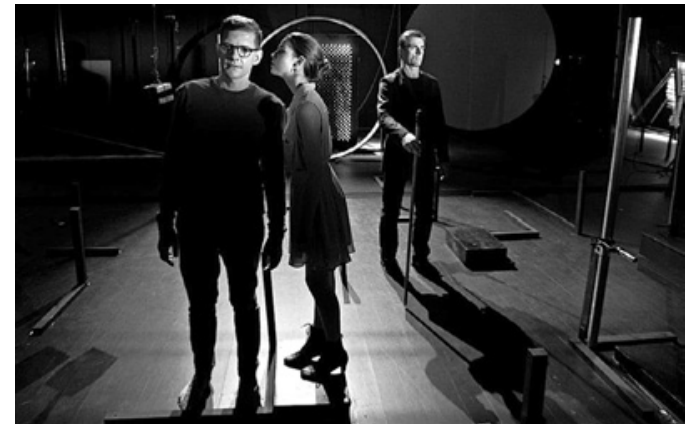

não contrata necessariamente actores: os performers podem ser cidadãos comuns, cantores, bailarinos, homens musculados, crianças ou anões.

Esta companhia não é um teatro de actores, pelo que não é o ambiente ideal para desenvolver uma linguagem individual ou de grupo. Grande parte das marcações são feitas antes da chegada dos performers: Kirsten Dehlholm concebe as imagens na sua cabeça e desenha-as como rascunhos muito simples. Quando um performer entra no espaço cénico tem de ser extremamente disciplinado e tem de se adaptar a uma espacialidade exigente. Os performers têm de perceber que essa espacialidade é, em si, um contador de histórias, um jogador com o qual têm de estabelecer relações dramáticas. 0 performer activa o espaço com a sua presença, quer na sua condição de performer, quer enquanto personagem.

0 papel do encenador está mais próximo de um planear do espaço, dos objectos e do desenho geral, do que do dirigir actores ou estabelecer um ambiente dramático no palco. Dai o comentário de Kirsten Dehlholm:

Penso que seria um desafio trabalhar com actores treinados no teatro tradicional ou num teatro psicológico. Não tenho trabalhado muito com actores. Numa perspectiva tradicional, um elenco tem uma educação completamente diferente e tem um ponto central diferente do meu. Gostaria, na verdade, de explorar como os textos psicológicos jogariam com a minha arte performativa, onde os eventos cénicos e os espaços têm um papel importante na história. (Rehearsal Matters 2012, t. m.)
Site Seeing Zoom, de Morten Søndergaard enc. Kirsten Dehlholm, 2001, (Morten Nielsen.) fot. Roberto Fortuna, Cortesia Hotel Pro Forma.

Laughter in the Dark (fotografia de ensaio) a partir de Vladimir Nabokov,

enc. Kirsten Dehlholm, 2012, (Johannes Lilleøre Coco Hjardemaal, Niels Anders Thorn), fot. Claudi Thyrrestrup, Cortesia Hotel Pro Forma. 
Desde que começou a usar textos, a companhia tem adaptado partes de romances, poemas e peças de teatro, mas tem também encomendado textos, narrativas e poemas a escritores, poetas e filósofos. Quando se trata de uma peça musical, o libreto é adaptado ou encomendado a um ou mais compositores.

A maneira como o texto é tratado e refeito em cena nunca é dramático num sentido tradicional: nunca é um teatro baseado no conflito ou no enredo. 0 teatro, que fazem, é um estudo sobre o texto e a imagem - sobre o modo como esses dois elementos podem existir juntos sem se ilustrarem um ao outro. 0 texto é colocado contra a imagem, o espaço, a acústica e a paisagem sonora. Como funciona o texto como um jogador, num certo espaço? Como se dá a ouvir o texto sob certas condições - escuridão completa, por exemplo? Em suma, como muda o significado do texto em determinadas condições?

Actualmente, Kirsten Dehlholm parece estar sobretudo interessada na complexidade do texto e da imagem. Está interessada no modo como os significados podem mudar e deslocar-se. Está de igual forma interessada no processo de construção de significado, e nas suas variáveis - ou seja, na maneira como alguém pode construir e o que significa essa construção. Nesse sentido, a directora artística enfatiza a importância da idade e do género dos performers quando se trata de apreender um texto e o seu conteúdo. Assim conclui:

Numa sociedade baseada no texto como a nossa, o uso de texto determina em grande medida a forma como as pessoas percebem e apreendem as coisas. Então é necessário e interessante investiga como um texto pode adquirir novos significados, dependendo da sua forma e da apresentação em contextos de espectáculo. (Theil/ Dehlholm 2003: 102, t.m.)

É importante perceber como o texto toma forma em situação de espectáculo. Pode ser disfarçado no discurso por músicas, projectado numa superfície, gravado, dito por linguagem gestual, sussurrado ou apresentado como um livro. 0 filósofo dinamarquês Per Aage Brandt, que já escreveu para o Hotel Pro Forma, expressou o seu descontentamento pelo facto de os seus textos serem ditos em voz alta. Acrescenta ainda que nunca aceitou bem o entoar dos seus textos porque eles deveriam soar exactamente ao que os textos são. Quando se trata da fala, para um performer que realmente diz o texto, a maior preocupação é como dizer o texto. Kirsten Dehlholm usa a expressão "entregar o texto", porque está preocupada não só em como este é enunciado, mas também como funciona em relação com o meio e, finalmente, como é recebido e apreendido pelos espectadores. Para cada texto há um estilo apropriado de "entrega".

Olhando para as produções do Hotel Pro Forma identificamos este estilo de entrega como sendo independente de qualquer diálogo dramático ou situação teatral. 0 texto para o espectáculo, escrito ou falado, não necessita de ter um diálogo dramático, uma estrutura de intriga, uma narração linear, não tem de estar relacionado com o mundo conhecido. Como escreve Mike Pearson, performer e encenador galês: 


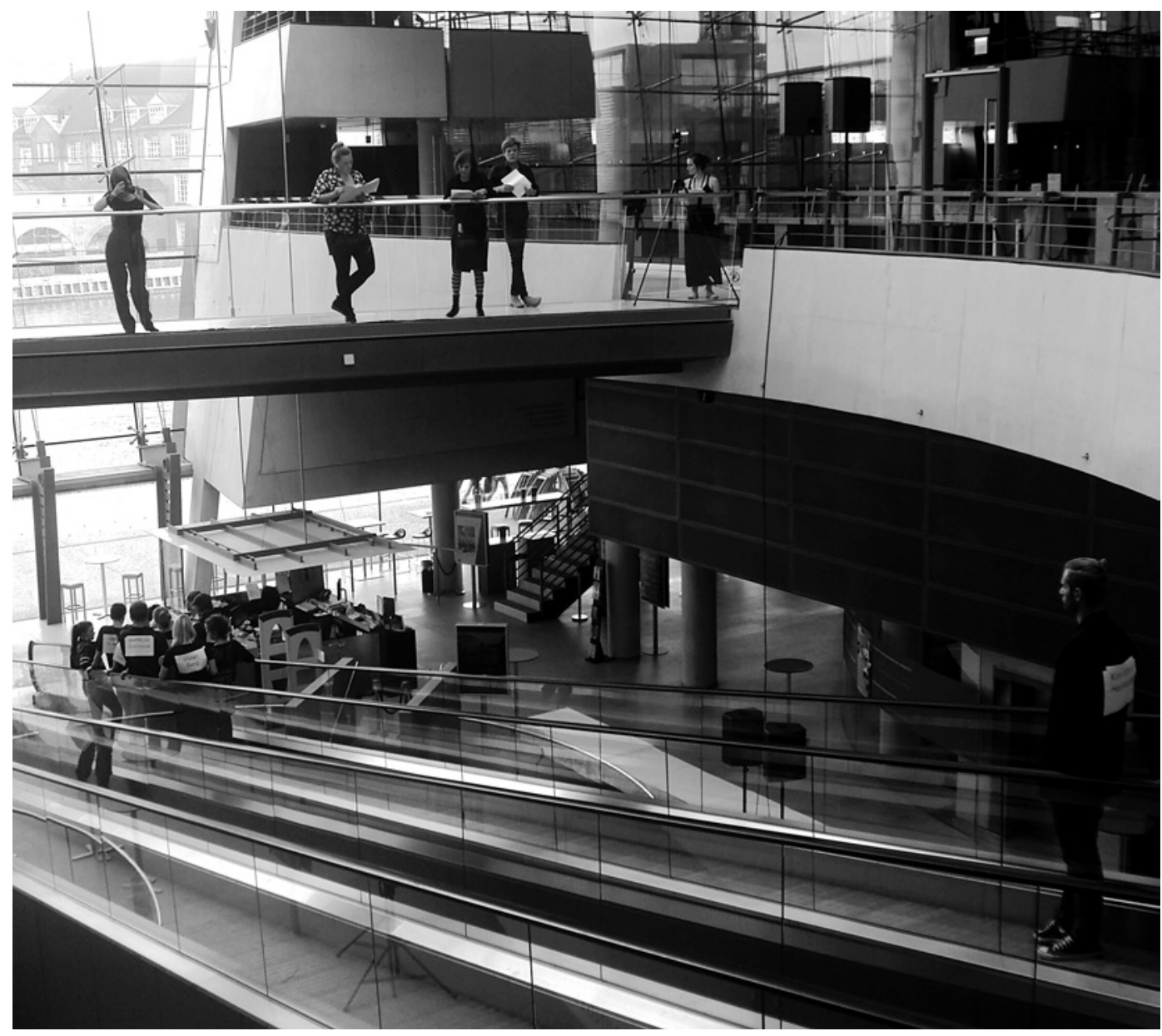

Oktobernat

(fotografia de ensaio), de Johannes V. Jensen, enc. Kirsten Dehlholm, 2011, fot. Maria Carneiro, Cortesia Hotel Pro Forma.

[...] esta forma de diálogo dramático em que as personagens falam cara-a-cara trocam informações e expressam os seus sentimentos, e constantemente se referem a eventos fora do palco, em qualquer outra parte, no mundo real. (Pearson 2010: 167, t.m.)

A companhia adoptou conscientemente o texto como nova variável no seu processo de trabalho. Mas, se o texto é entregue independentemente de qualquer estrutura dramática ou ligação com a situação performativa, o que é que mantém o espectáculo como um todo? A resposta é: o espaço e o desenho do espaço. Per Theil escreveu:

A estrutura e natureza do espaço é, se alguma coisa, o enredo efectivo. (Theil/ Dehlholm 2003: 11, t.m.)

A companhia tende a encenar o espaço no sentido de Ihe proporcionar uma outra vida, uma segunda vida, e o público experiencia-o de maneira diferente. A importância extrema conferida quer ao espaço como contador de histórias quer à de "entregar" (/proferir) o texto ajudam a fazer do Hotel Pro Forma um teatro de texto não dramático. É tudo, incluindo o texto, muito material e concreto, não dando origem a estruturas dramáticas tradicionais. Como espectadora, fui percebendo que a falta de drama pode afectar directamente a maneira como o público apreende o espectáculo. Um espectador não sai de um espectáculo do Hotel Pro Forma sentindo-se extasiado ou cheio de adrenalina. 0 espectáculo opera junto da plateia num processo lento, e trabalha gradualmente no interior do espectador. Cria impressões que ficam.
Em 1987, para a primeira produção em que foram utilizadas palavras, Ater, a companhia pediu a uma das mais reputadas escritoras dinamarquesas, Inger Christensen's (1935-2009) para escrever um texto baseado num conceito visual. Durante uma hora e meia quatro actores apresentaram um texto poético que resultou num diagrama visual.

Em 1989, Carpe Carpe Carpe foi apresentado por crianças de sete e oito anos de idade. 0 texto poético de Per Aage Brandt lidava com questões de adultos, tais como o tempo, a natureza, a tortura, o sexo e a escrita. As crianças aprenderam o texto de cor e diziam-no com a sua presença imediata, com movimentos ora inconscientes ora propositados e com uma monotonia não dramática nas suas vozes. As crianças não interpretaram o texto, elas "entregavam-no" (proferiamno), simplesmente.

Em 2001, para a performance-instalação Site Seeing Zoom, a companhia pediu ao poeta e artista sonoro Morten Søndergaard, e escrita de um texto para um conceito visual que relacionava o cérebro humano e a memória com a memória virtual de computadores. Num ambiente altamente digital, o público ouvia quatro vozes gravadas e via uma sequência não linear de imagens. A interacção acontecia entre um único performer e essas imagens, bem como com a paisagem sonora que ocupava o espaço e ecoava as imagens. 0 público, em pé, movimentava-se livremente em volta da plataforma em forma de cruz e era a experiência disso tudo fazia o espectáculo. 


\section{Ater, \\ de Inger Christensen, \\ enc. Kirsten Dehlholm, \\ 1987, (Kirsten Dehlholm) \\ fot. Roberto Fortuna,}

Cortesia Hotel Pro Forma.
Em Outubro de 2011 a companhia colaborou com a Biblioteca Real para criarem um pequeno espectáculo para a Noite Cultural de Copenhaga. Kirsten Dehlholm estava fascinada a olhar para as pessoas nos dois longos tapetes rolantes no centro do edificio da biblioteca. Pensou então em usar um antigo conto dinamarquês chamado Oktobernat (Noite de Outubro) de 1898 de Johannes V. Jensen. 0 conto foi dividido em frases e cada frase foi atribuida a uma pessoa diferente. Estavam lá cinquenta pessoas, entre elas, crianças, idosos, adultos e jovens, pessoas que responderam à chamada, velhos amigos da companhia e até mesmo antigos performers. As frases foram distribuídas entre os performers e foi feita uma composição. Os performers pisavam o tapete rolante, sozinhos ou em grupo e, quando chegava a sua vez, diziam a sua frase. Visualmente, foi uma constelação de pessoas a descerem e subirem os tapetes rolantes - a encenação de uma narrativa visual. 0 exercício foi uma tentativa de contar a história como um todo, enquanto se observavam diferente pessoas a subir e descer. 0 público estava no topo e no fundo dos tapetes rolantes, em pontes que atravessam o edifício e em passagens laterais, pelo que cada espectador tinha uma experiência diferente do espectáculo. Afinal, é o efeito visual e a percepção da cena, que o espectador tem, o que realmente preenche a experiência de ir ao teatro.

No Outono de 2012, The One Who Whispers estreia em Copenhaga. Neste espectáculo o texto é projectado por detrás e acima da plateia, para quando o performer entrar no espaço cénico e começar a andar ao longo da passerelle, poder ler o que está a ser projectado. Este dispositivo vai afectar a maneira de dizer e de ouvir o texto. Aos performers foi pedido para desempenharem o papel, mas para não exagerarem.

No Outono de 2014 vai estrear outro espectáculo. Laughter in the Dark parte do romance com o mesmo nome de Vladimir Nabokov, de 1938. 0 desafio assumido para este projecto é o de contar um enredo, de optimizar o jogo e a interacção entre o texto e o espectáculo. Pela

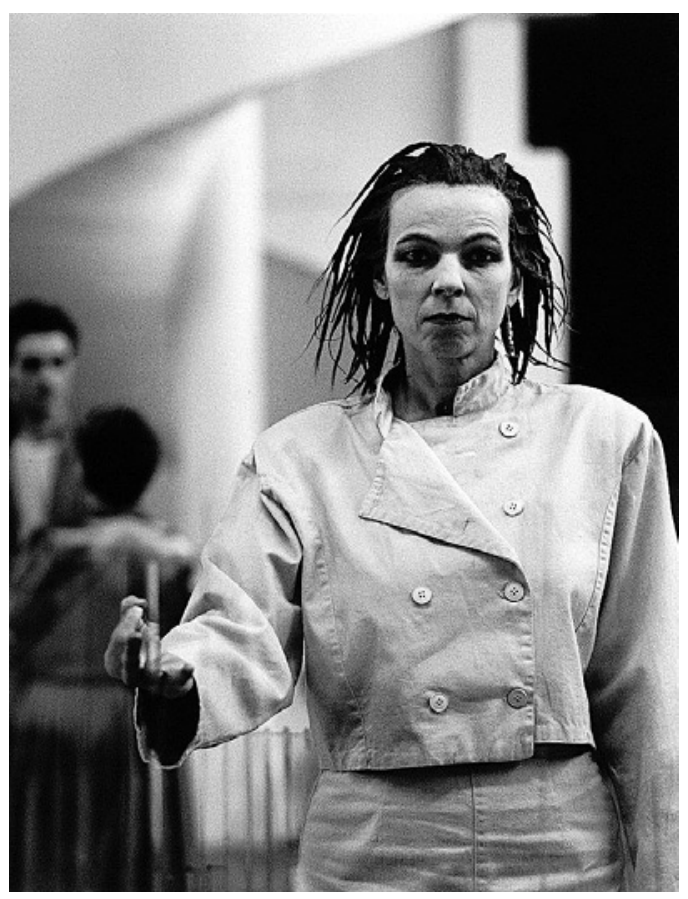

primeira vez num espectáculo desta companhia, personagens vão reconhecer-se umas às outras através do diálogo. Assim alguns truques foram desenvolvidos de modo que o actor seja a personagem. 0 elenco composto por três actores profissionais já foi escolhido e Kirsten Dehlholm tem estado a reescrever o guião tendo em consideração as cenas dramáticas do romance, seguindo um modelo/fórmula de intriga especialmente desenvolvido para este projecto.

Hoje em dia, como podemos perceber, o Hotel Pro Forma está fortemente empenhado na investigação sobre o papel do texto nos espectáculos. Tem-se dito que presenciamos um ressurgimento do teatro de texto na Europa. Esta companhia pode querer seguir esta orientação, assim como pode querer apresentar um novo lado do seu trabalho para assim não ficar "prisioneira" de um teatro simplesmente visual ou conceptual. Nesse sentido, Kirsten Dehlholm afirma que o Hotel Pro Forma ainda não abraçou o dramático completamente, mas acrescenta:

\footnotetext{
Eu gosto mesmo de mostrar novos lados das artes ... para dar a ver que o Hotel Pro Forma é também capaz de lidar com qualquer tipo de coisas ... para as pessoas dizerem que o Hotel Pro Forma é só um teatro visual - não! Nós não somos só teatro visual, há sempre muito e muito mais. (Entrevista 2011, t.m.)
}

\section{Referências bibliográficas}

Entrevista com Kirsten Dehlholm em 29/11/2011 (gravada em video). PEARSON, Mike (2010), Site-Specific Performance, Londres, Palgrave Macmillan.

Rehearsal Matters, http://www.rehearsalmatters.org/interview/kirstendelholm, acedido em 13/5/2012.

THEIL, Peter / DEHLHOLM, Kirsten / QVORTRUP, Lars / FORTUNA, Roberto (2003) Hotel Pro Forma: The Double Staging: Space and Performance, Copenhaga, The Danish Architecture Press. 